Criar Educação, Criciúma, v. 9, ㄲo 3, ago/dez. 2020 - PPGE - UNESC - ISSN 2317-2452

\title{
O ENSINO DE HISTÓRIA NO BRASIL: UM APANHADO ACERCA DOS CONTEXTOS E METODOLOGIAS, NO TEMPO PRESENTE
}

\author{
Paulo Augusto Tamanini ${ }^{1}$ \\ Gislânia Dias Soares²
}

\begin{abstract}
RESUMO
O presente artigo traz em seu escopo uma reflexão acerca do Ensino de História e suas abordagens metodológicas, contestando práticas memorialistas e/ou tradicionais e discutindo a implementação de práticas inovadoras em sala de aula. Na primeira parte do estudo tecemos uma discussão teórica sobre a temática e suas implicações para a prática docente. $\mathrm{Na}$ segunda parte apresentamos o resultado de uma pesquisa do tipo estado da arte, onde realizamos um levantamento da produção sobre teoria, metodologia e ensino de História dos títulos e resumos entre os anos de 2008 a 2018, no Catálogo de Teses e Dissertações da Coordenação de Aperfeiçoamento de Pessoal de Nível Superior - CAPES, espaço que se encontram as produções realizadas nos programas de pós-graduação stricto sensu de universidades públicas e privadas do Brasil.
\end{abstract}

Palavras-chave: Teoria; Metodologia; Ensino de História; Estado da Arte.

\section{THE TEACHING OF HISTORY IN BRAZIL. A SUMMARY ABOUT THE CONTEXTS AND METHODOLOGIES, AT PRESENT TIME}

\begin{abstract}
The present article brings in its scope a reflection about History Teaching and its methodological approaches, contesting memorialist and / or traditional practices and discussing the implementation of innovative practices in the classroom. In the first part of the study we made a theoretical discussion about the theme and its implications for teaching practice. In the second part we present the result of a state-of-the-art research, where we conducted a survey of the production on theory, methodology and teaching of History of titles and abstracts between the years 2008 to 2018, in the Catalog of Thesis and Dissertations of the Coordination of Improvement of Higher Level Personnel - CAPES, a space where productions are held in the stricto sensu graduate programs of public and private universities in Brazil.
\end{abstract}

Keywords: Theory; Methodology; History teaching; State of art.

\footnotetext{
${ }^{1}$ Pós-Doutor em História (CAPES/UFPR). Doutor em História (CAPES/UFSC). Professor do Programa de Pós-Graduação em Ensino (UFERSA/UERN/IIFRN). Coordenador do Grupo de Pesquisa Imagem e Ensino (CNPq/UFERSA). Professor Orientador do Programa de Pós-Graduação em Ensino. Email: professor@tamanini.com.br - Orcid: https://orcid.org/0000-0001-6963-2952
}

\footnotetext{
2 Universidade Federal Rural do Semiárido (UFERSA). Mestranda do Programa de Pós-Graduação em Ensino- POSENSINO
} 


\section{Introdução}

O mundo no qual vivemos está em constante transformação e expansão, marcado por incertezas, provisoriedade e/ou transitoriedade (HABERMAS, 2000; BUCK-MORSS, 2002). A dinâmica de transitoriedade das certezas e a falta das permanências influenciam também o cenário educacional, impulsionando inquietações sobre como promover um ensino que contemple as exigências da atualidade. Parece não caber mais às escolas um modelo de ensino apenas generalizante, fragmentado e reducionista, nem tão pouco uma prática pedagógica dita conservadora com um processo de ensino pautado apenas na transmissão de conteúdos pelos docentes. Em consequência, se faz urgente a adoção de uma abordagem contextualizada e problematizadora do conhecimento nas nossas salas de aula. Tal demanda induz que as instituições educacionais precisem revisitar e refletir sobre o entendimento de disciplina, educação, escola, aluno, sociedade e conhecimento.

Sendo assim, ensinar História nesse novo milênio, em que o passado parece estar cada vez mais sendo destituído de importância pelas novas gerações, tornou-se imperativo "mostrar que é possível desenvolver uma prática de ensino de História adequada aos novos tempos (alunos): rica de conteúdo, socialmente responsável e sem ingenuidade ou nostalgia" (PINSKI; PINSKI 2008, p. 19).

Esse artigo discute o ensino de História, na tentativa de responder a questões que têm persistido ao longo da história da disciplina: quais conteúdos e métodos são os mais adequados para ensinar História a todos os níveis. Para Bittencourt (2011), essa indagação deve estar presente nos cursos de formação inicial, bem como na formação continuada dos professores, para a efetivação de uma prática pedagógica que responda as demandas das atuais gerações. Destarte, o desafio que se impõe ao professor de História é a heterogeneidade encontrada em sala de aula, composta por diferentes sujeitos históricos e sociais, portadores de diferentes anseios frente ao mundo contemporâneo. 
Teoria, metodologia e ensino de História

(...) É impossível compreender seu tempo para quem ignora todo o passado; ser uma pessoa contemporânea é também ter consciência das heranças, consentidas ou contestadas.

René Remond

Consensualmente quando falamos em História remetemo-nos à antiguidade, ao passado. O termo "história" era empregado para constituir relatos sobre as experiências dos homens no tempo como escritos em pedras de túmulos, anéis de reis, dentre outros aportes, e apenas no início do século XIX começam a ocorrer a sistematização do saber histórico de modo autônomo e particular, com a figura do historiador e o emprego da História no sentido de investigação (FIALHO; MACHADO; SALES, 2016). É imperiosamente necessário caracterizar, embora que brevemente, as três principais correntes do pensamento histórico que exerceram acentuada presença no ensino de História: Positivismo, Marxismo e Escola dos Annales.

No Positivismo, a História, como área de conhecimento e disciplina, foi marcada por uma metodologia rigorosa e, como um saber genuinamente acerca do passado. Essa tendência ficou conhecida como positivismo ou, Escola Metódica. De acordo com tal entendimento, caberia aos estudos da área de humanas estabelecer métodos e técnicas semelhantes aos das Ciências Naturais e o conhecimento produzido deveria ser sempre verdadeiro, isto é, o conhecimento positivo da História (FIALHO; MACHADO; SALES, 2016). Destarte, a concepção positivista de História é vista de forma inquestionável, verticalizada, onde o aluno é um sujeito passivo, realizando atividades meramente mecânicas e descontextualizadas. Augusto Comte, é considerado o pai do Positivismo.

Segundo Fialho, Machado e Sales (2016), a corrente Positivista foi posta em questão pelo Marxismo (também chamado de Materialismo Histórico), tendo como expoentes Karl Marx e Friedrich Engels, na segunda metade do século XIX. Essa corrente tenta explicar as mudanças históricas através das condições materiais, modos de produção ou disputa entre classes sociais existentes em determinado período histórico. No que tange ao ensino de História, a referida concepção marxista aponta que a disciplina pode se tornar um instrumento revolucionário, contribuindo 
para a formação da identidade de classe e, consecutivamente, formando cidadãos críticos e revolucionários.

Contudo, foi no início do século XX, que o campo da História passou por uma das mais significativas mudanças, a saber: a Escola dos Annales (História Nova). Para essa corrente historiográfica o estudo da História é o estudo do cotidiano de um povo, do modo como viviam, se organizavam, produziam ou se relacionavam política e socialmente em tempos e espaços diversos. O Conceito de fonte histórica trazida por essa Escola

ampliou-se significativamente, entendendo-a como vestígios de naturezas diversas deixados por sociedades do passado. $\mathrm{O}$ historiador, contudo, deve dominar métodos de interpretação, entendendo que as fontes deveriam ser criticadas e historicizada. Nesse caso, a utilização das fontes históricas não trata de buscar as origens ou verdades de fatos, como defendiam os positivistas (FIALHO; MACHADO; SALES, 2016, p. 1051).

Nessa perspectiva, a diversidade de fontes históricas fez com que os historiadores pudessem utilizar pinturas, fotografias, objetos, filmes, móveis, roupas e músicas como fonte. Consequentemente, a noção de documento escrito também se multiplicou e passou-se a recorrer a cartas, diários, jornais, receitas culinárias etc. Entre os autores que se destacaram nessa Escola podemos citar: Marc Bloch, Lucien Febvre, Fernand Braudel, Jacques Le Goff e Pierre Nora.

Na década de 80, segundo Bittencourt (2011), teve início um período de intensa discussão e renovação do ensino de História, acerca de seu método de ensino. $\mathrm{O}$ debate girava em torno da sua caracterização enquanto disciplina exigir do aluno apenas "saber de cor" nomes, datas e personagens ilustre, numa abordagem tradicional do ensino. Tais críticas ao ensino de História voltado para uma História tradicional, impulsionou reformulações curriculares e constatou-se a urgência da renovação de conteúdos e métodos por parte de muitos professores, uma vez que estes enfrentavam nas salas de aula, alunos com diferentes condições sociais e culturais. Materiais didáticos foram sendo substituídos, introduzindo-se nas aulas depoimentos, textos de revistas, excertos de notícias de jornais, filmes, dentre outros.

Surge a necessidade de uma mudança geral no ensino de história. O método tradicional pautado na memorização e reprodução do conhecimento, onde o aluno é 
passivo na relação ensino-aprendizagem precisa ser substituído, dando lugar a contextualização em relação aos conteúdos estudados. É mister o professor saber que: "quanto mais o aluno sentir a história como algo próximo dele, mais terá vontade de interagir com ela, não como uma coisa externa, distante, mas como uma prática que ele se sentirá qualificado e inclinado a exercer" (KARNAL, 2008, p. 28).

Nesse cenário, o que se deve ensinar na disciplina de história? Qual seleção de conteúdos torna essa disciplina atraente para os alunos? Quais conteúdos garantem uma formação adequada? Que metodologia é capaz de produzir um diálogo entre o que aconteceu e foi produzido historicamente e o que é trabalhado em sala de aula, contextualizado com a realidade e vivência do aluno?

Estudos de Karnal (2008) têm demonstrado a importância de o docente dominar e abordar coerentemente o processo histórico, observando permanências e mudanças que, na vida social, ressoam do passado até nossos dias. Na seleção de conteúdos, o professor precisa primar por assuntos congruentes com os objetivos da disciplina, com as competências e habilidades que deverão ser desenvolvidas pelo aluno ao longo de sua formação considerando as reais necessidades dos mesmos. Outra possibilidade na escolha dos conteúdos, passa pelo momento vivido, considerando as problemáticas atuais.

Para dar conta da complexidade do processo educativo e promover no aluno o sentimento de pertencimento a história, o professor deve procurar escapar dos determinismos no tocante a abordagem dos assuntos, pressupondo construir um diálogo entre passado e presente, evitando o conhecimento neutro e acabado sobre fatos que aconteceram em outras sociedades e épocas. Para Bittencourt (2011) adotar uma postura pedagógica inovadora em sala de aula requer estudo, compromisso e responsabilidade por parte do ensinante, para que sua ação docente tenha sentido e seja eficaz.

Nesse viés, o fazer docente do professor de história caminha para a inserção de novas metodologias, oportunizando ao discente participar ativamente do processo ensino-aprendizagem, discutindo e problematizando os conteúdos para construir um saber pensante e crítico. Se constitui como alternativa ou possibilidade, as concepções críticas e dialógicas. O Método dialético quando utilizado no ensino de História e demais disciplinas escolares promove o desenvolvimento do espírito crítico 
Criar Educação, Criciúma, v. 9, ํo 3, ago/dez. 2020 - PPGE - UNESC - ISSN 2317-2452

no aluno, haja vista a possibilidade de discutir o objeto problematizando-o. Nessa abordagem metodológica as coisas não são analisadas na qualidade de objetos fixos, mas em movimento: nenhuma coisa está "acabada", encontra-se sempre em vias de se transformar, desenvolver; o fim de um processo é sempre um começo de outro (BITTENCOURT, 2011).

Buscando promover um ensino de História que integra o saber do aluno e da comunidade aos conteúdos apresentados pelas propostas curriculares, se apresenta o Método dialógico. Conforme sublinha Bittencourt (20011, p. 234), "sua base reside na aquisição social do conhecimento: Conhecer é um evento social, ainda que com dimensões individuais". Paulo Freire destaca e defende a importância do método dialógico em sala de aula, onde o professor pelo diálogo estabelecido com o aluno apresenta a discussão/problemática, considerando que o discente possui um conhecimento prévio sobre o objeto de estudo. Segundo Freire (1986, p.124)

\section{O diálogo é a confirmação conjunta do professor e dos alunos no ato comum de conhecer e re-conhecer o objeto estudado. Então, em vez de transferir o conhecimento estaticamente, como se fosse uma posse fixa do professor, o diálogo requer uma aproximação dinâmica na direção do objeto" (apud BITTENCOURT, 2011, p. 235).}

Nessa ótica, professor e aluno aprendem justos, partilhando saberes e vivências essenciais para a construção de uma aprendizagem significativa.

Ainda no que concerne ao ensino de História, Bittencourt (2011) destaca que o mesmo pode se articular com outras disciplinas numa perspectiva interdisciplinar, pois muitas vezes a disciplina de História não dará conta sozinha de explicar um referido acontecimento, e por isso, faz-se necessário buscar respostas em outras áreas do conhecimento. Acredita-se que é a partir dos pontos de convergência entre as disciplinas que pode haver o entendimento de uma realidade ou a resolução de um problema. As situações com as quais nos deparamos no dia a dia não são isoladas. Afinal, vivemos em uma sociedade complexa onde a mais simples questão precisa de um olhar mais abrangente, e as propostas interdisciplinares possibilitam desenvolver esse olhar mais apurado.

A metodologia interdisciplinar em seu exercício requer como pressuposto uma atitude especial ante o conhecimento, que se evidencia no reconhecimento das competências, incompetências, possibilidades e limites 
Criar Educação, Criciúma, v. 9, nํ3, ago/dez. 2020 - PPGE - UNESC - ISSN 2317-2452 da própria disciplina e de seus agentes, no conhecimento e na valorização suficientes das demais disciplinas e dos que a sustentam (FAZENDA, 1994, p. 69).

Todavia, essa integração não é uma atividade fácil, uma vez que demanda um aprofundamento na área, além de um método comum a todas as disciplinas. Encontramo-nos com inúmeras barreiras: de ordem material, pessoal, institucional e formativa para sua efetivação em sala de aula. Entretanto, tais barreiras poderão ser transpostas pelo desejo de criar, de inovar, de ir além, buscando a construção de um conhecimento coletivo. (FAZENDA, 1993).

É possível perceber que, nesses embates e discussões em torno de proposições sobre o ensino de História o professor ocupa papel ímpar. Ele é responsável por gerir esse processo mutante de construção de saberes, tendo como desafio cumprir um currículo extenso e formar sujeitos críticos e autônomos, estabelecendo uma articulação entre o patrimônio cultural da humanidade e o universo cultural do aluno. Nenhuma metodologia ou técnica de ensino acontece de maneira exitosa se o professor não se lançar como mediador entre o conhecimento historicamente acumulado e o aluno (BITTENCOURT, 2011). Nessa direção, o professor de História deve estimular o aluno a aprender a se movimentar no tempo, a conseguir situar-se na história das sociedades para compreender a sua.

\section{Estado da arte: descrição e análise}

A partir daqui, elencamos um sumário, uma síntese, um apanhado, um levantamento acerca do que já foi produzido sobre teoria, metodologia e ensino de História. Para tanto, consultamos o Catálogo de Teses e Dissertações da Coordenação de Aperfeiçoamento de Pessoal de Nível Superior (CAPES), ferramenta que possibilitou o acesso e a divulgação da produção científica a nível de stricto sensu (mestrado e doutorado) em todo o país, para criarmos um estado da arte.

Para Messina (1998, p. 01) "um estado da arte é um mapa que nos permite continuar caminhando". Ainda segundo a autora, "[...] Em um estado da arte está presente a possibilidade de contribuir com a teoria e prática de uma área do conhecimento". (apud ROMANOWSKI; ENS, 2006, p. 40). A pertinência desse tipo de trabalho reside na abrangência desses estudos em apontar os caminhos que vêm 
Criar Educação, Criciúma, v. 9, ㄲo 3, ago/dez. 2020 - PPGE - UNESC - ISSN 2317-2452

sendo seguidos e quais aspectos são abordados em detrimento de outros, nesse tempo de avanços constantes na ciência e na tecnologia (ROMANOWSKI; ENS, 2006).

Romanowski e Ens (2006) afirmam que para desenvolver a pesquisa tipo estado da arte é necessário compreendê-la como um estudo descritivo e analítico, que segue etapas definidas para que se alcance o objetivo desejado. Desse modo, a presente pesquisa foi realizada no dia 18 de setembro de 2018, no Catálogo de Teses e Dissertações da CAPES, passando pelas seguintes etapas:

a) Definição dos descritores: "metodologia"; "teoria"; "ensino de história".

b) Acesso ao site <www.capes.gov.br>, clicando em Plataformas e, em seguida, em Catálogo de Teses, para levantamento dos resumos e palavras-chave.

c) Com esta delimitação foram encontrados 196.945 resultados. Na tentativa de enxugar esse resultado extenso, fomos refinando nossa pesquisa conforme as possibilidades que o Catálogo de Teses e Dissertações da CAPES dispunha. Na sequência marcamos no filtro Ano, realizando nossa delimitação temporal de 2008 a 2018. O número encontrado diminuiu para 132.213. Continuamos nossa pesquisa clicando em Grande área conhecimento e foram selecionadas somente aquelas intituladas Ciências Humanas, uma vez que a disciplina de História pertence a esta área. O resultado baixou mais um pouco chegando a 27.602 estudos. Em Área conhecimento refinamos novamente, selecionamos somente as disciplinas que se relacionavam com História, o que resultou em 1.669 trabalhos. No campo Área de Concentração, aplicando o critério da especificidade temática, foi selecionado somente o termo Ensino de História por se relacionar com os descritores utilizados nesta pesquisa, chegando ao resultado de 153 produções. Em seguida, acessamos na Plataforma Sucupira, às páginas das 153 obras para ler títulos, resumos e palavras-chave. 
d) Para a análise das publicações a partir dos resumos, criou-se uma tabela com a seguinte estrutura: título, autor, orientador, ano, instituição e programa stricto sensu.

e) Análise e elaboração das considerações finais.

No total, foram encontradas no Catálogo de Teses e Dissertações da CAPES 153 obras, porém foram excluídas 150, por não apresentarem ligação com os descritores utilizados, restando ao final da seleção, 03 dissertações. No entanto, é mister destacar que das 03 dissertações restantes, apenas 01 se aproximou do nosso tema, por contemplar 02 dos 03 descritores. Quando fizemos o download das produções para leitura foi que percebemos essa realidade, uma vez que lendo título, resumo e palavras-chave as informações são insuficientes para fazemos a análise dos trabalhos.

No quadro a seguir, examinaremos as publicações encontradas no Catálogo de Teses e Dissertações da CAPES considerando em sua estrutura: título, autor, orientador, ano, instituição e programa stricto sensu.

\section{QUADRO DAS OBRAS COLETADAS}

Fonte: Quadro organizado pela autora, com base nos dados colhidos no site da CAPES.

\begin{tabular}{|c|c|c|c|c|c|}
\hline Título & Autor & Orientador & Ano & Instituição & $\begin{array}{l}\text { Stricto } \\
\text { Sensu }\end{array}$ \\
\hline $\begin{array}{l}\text { Ensino de História e projeto } \\
\text { integrado: possibilidades para a } \\
\text { geração de aprendizagens. }\end{array}$ & $\begin{array}{l}\text { Deise } \\
\text { Angélica } \\
\text { Pasquali } \\
\text { Bascheira }\end{array}$ & $\begin{array}{l}\text { Katani } \\
\text { Maria } \\
\text { Nascimento } \\
\text { Monteiro } \\
\end{array}$ & 2015 & UCS/RS & Profissional \\
\hline $\begin{array}{l}\text { O ensino de História nos anos } \\
\text { iniciais do Ensino Fundamental: as } \\
\text { políticas da Secretaria Municipal de } \\
\text { Educação do Rio de Janeiro e a } \\
\text { perspectiva do multiculturalismo. }\end{array}$ & $\begin{array}{l}\text { Raquel } \\
\text { Brayner da } \\
\text { Silva }\end{array}$ & $\begin{array}{l}\text { Alessandra } \\
\text { Carvalho }\end{array}$ & 2016 & UFRJ & Profissional \\
\hline $\begin{array}{l}\text { O ensino de História na Educação } \\
\text { Básica: reflexões sobre conceitos e } \\
\text { metodologia. }\end{array}$ & $\begin{array}{l}\text { Regina das } \\
\text { Graças } \\
\text { Figueredo } \\
\text { Godinho } \\
\text { Drehmer }\end{array}$ & $\begin{array}{l}\text { Amândia } \\
\text { Maria de } \\
\text { Borba }\end{array}$ & 2008 & UNIVALI/SC & Acadêmico \\
\hline
\end{tabular}

Analisando o quadro acima, percebemos que a produção acadêmica sobre 0

tema teoria, metodologia e ensino de História tem sido tímida e não está entre as mais discutidas na atualidade, apesar da importância que possui na formação do professor. Em um universo de 153 estudos relacionados ao ensino de História, no tocante a 
teoria e metodologia encontrar apenas 03 publicações, ou seja, menos de $2 \%$, torna patente a necessidade de pesquisa nessa seara. Observamos também, que as pesquisas sinalizam uma tendência para os programas de mestrado profissional, em Instituições de Ensino Superior - IES privadas. Com relação à Região, os dados demonstraram que a região Sul é a que mais pesquisou sobre o tema.

No que diz respeito ao tipo de pesquisa, a leitura dos resumos das 03 obras revelou que somente Drehmer (2008) informou claramente o tipo de pesquisa realizada, a saber, qualitativa, utilizando-se da metodologia descritivo-interpretativa, bem como dos procedimentos para a coletas de dados: análise documental e observação. Esse tipo de abordagem é bastante comum em pesquisas educacionais. Segundo Bogdan e Biklen (1994), a investigação qualitativa possui cinco características: o investigador é o instrumento principal da coleta de dados, e o ambiente natural é a fonte direta dos dados; é descritiva e os pesquisadores registram os dados e procuram interpretá-los em sua totalidade; os pesquisadores preocupamse com o processo e não com o resultado; o significado atribuído às coisas e à vida pelas pessoas recebe atenção especial do pesquisador e a análise dos dados passa por um processo indutivo.

Outra lacuna percebida em ambos os estudos foi a ausência da base teórica de suas produções nos resumos. Entendemos que esse dado em especial é muito importante em um trabalho acadêmico, pois consiste numa síntese das discussões já feitas por outros autores sobre determinado assunto, servindo como embasamento para o desenvolvimento de um tema específico (MARCONI; LAKATOS, 2004). Buscando apresentar ao leitor deste artigo, os teóricos que embasaram os estudos aqui referidos, utilizamos a ferramenta Google para baixar as dissertações para leitura e extração dos dados pertinentes, haja vista os mesmos não se encontrarem nos resumos que tivemos acesso.

Identificamos nas 03 obras pesquisadas dois grupos teóricos: um relacionado ao ensino de História e práticas de sala de aula: Circe Maria Bittencourt, Leandro Karnal, Conceição Cabrini, Marília Cruz, Selva Guimarães Fonseca, André Joanilho, Sônia Nikitiuk, Jaime Pinsk, Carla Pinsk, Maria Auxiliadora Schmidt, Marlene Cainelli, Marcos Silva, Maria Aparecida Toledo, Carlos Henrique Barros, Flávia Heloísa Caimi, Arlete Gasparello, Ernesta Zamboni, Carmem Gil, Roger Chartier, André Fonseca, 
Ana Maria Monteiro e Bianca Barbalho Zucchi e outro ligado à pesquisas em educação e áreas afins ( Ivani Fazenda - Interdisciplinaridade, Maria Lúcia Aranha - Filosofia da Educação, Isabel Correa - Funções sociais da escola contemporânea, Jacques Delors - Educação, Dinéia Hypolitto - Professor reflexivo, José Carlos Libânio Organização e gestão escolar, Edgar Morin - Filosofia, Antonio Nóvoa - Formação de professores, Philippe Perrenoud - Formação de professores, Vera Candau - Didática, Ana Canen - Multiculturalismo, Stuart Hall - Identidade e diferença, Maurice Tardif Saberes docentes).

Analisando a base teórica das pesquisas, percebemos que em ambos os trabalhos houve a preferência pelos autores brasileiros consolidados na área de Ensino de História como: Circe Maria Bittencourt, Selva Guimarães Fonseca, Jaime Pinsk, Carla Pinsk, Maria Auxiliadora Schmidt, Marlene Cainelli e Marcos Antônio da Silva, o que nos aponta a pertinência de tais autores para estudos e produções posteriores.

Detectamos ainda, que o tema alvo de nossa pesquisa tem ficado aquém do esperado no quesito produção acadêmica. Fato esse que, desperta-nos para a necessidade de lançar um olhar sobre a prática pedagógica do professor de história, por entendermos que o sucesso do ensino-aprendizagem, envolve uma proposta didática de modo a conceber um conhecimento crítico e eficaz mediante os anseios da sociedade contemporânea.

\section{Conclusão}

Nosso intento ao conceber e escrever esse trabalho, foi oferecer subsídios ao professor no processo de ensino aprendizagem, apontando caminhos e possibilidades didáticas. O ambiente educacional na conjuntura atual demanda saberes, competências e habilidades múltiplas. Nessa linhagem, cabe ao profissional da educação, especificamente ao professor de História mostrar ao aluno a importância do ensino de História para a construção de um sujeito crítico e mais plural.

Impende ressaltar, ainda, que embora o processo de ensino-aprendizagem tenha sofrido mudanças ao longo da história, ainda há muito o que se discutir no encaminhamento dos novos procedimentos, haja vista, que o ensino deveria centrar- 


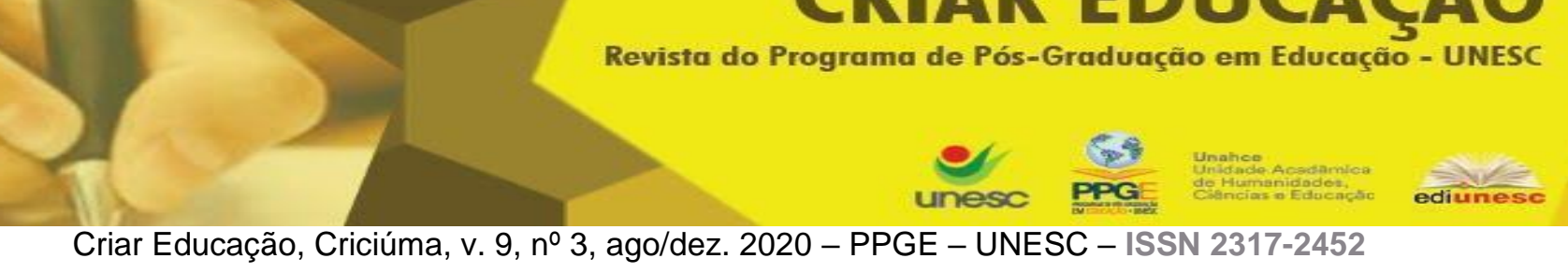

se em:

discussões temáticas, relacionadas com o cotidiano do aluno, seu trabalho e sua historicidade. O objetivo era recuperar o aluno como sujeito produtor da História e não como um mero expectador de uma história já determinada, produzida pelos heroicos personagens dos livros didáticos. (SCHIMDT; CAINELLI, 2004, P. 15)

Nessa direção, o professor de História deve estimular o aluno a aprender a se movimentar no tempo, a conseguir situar-se na história das sociedades para compreender a sua. Só assim estará atuando como um mobilizador da inteligência coletiva (SILVA, 2001), ajudando a criar e recriar o saber, contribuindo para o exercício da cidadania e, como consequência, para construir uma sociedade mais justa, igual, democrática, solidária e responsável.

Quanto ao estado da arte, permitiu um levantamento e análise do corpus formado por 153 resumos de pesquisas acadêmicas defendidas no Brasil sobre o ensino de História, no que concerne a teoria e metodologia, no período de 2008 a 2018, extraídos do Banco de Teses e Dissertações da CAPES. No entanto, somente 03 dissertações abordaram alguma especificidade da temática e, apenas $01 \mathrm{fez}$ referência a categoria conceito e metodologia. Os dados confirmam que essa área carece de atenção especial por parte dos pesquisadores, pois numa sociedade onde a transmissão de informação e conhecimento é tão veloz, o docente não pode ter uma prática engessada, tradicionalista, que se propõe a repetição de modelos que já não dão conta do universo da sala de aula.

A situação diagnosticada na pesquisa apresenta um aspecto promissor no tocante a possibilidade de novas produções, destinando-se àqueles professores de Histórias e de outras áreas que desejam aprimorar sua didática, bem como sua ação enquanto agente transformador da sociedade. Sabemos que artigos, ensaios e trabalhos como esse promovem discussões que resultarão em mudanças significativas no campo educacional.

A pesquisa apontou que há necessidade de se unificar o modo de colocar os resumos no banco de dados da CAPES, de forma que os dados informacionais sejam completos, possuindo apresentação do tema, problematização, objetivos, 


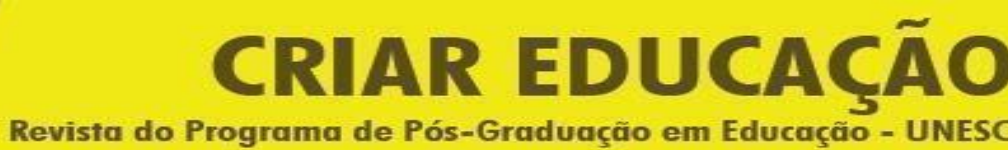
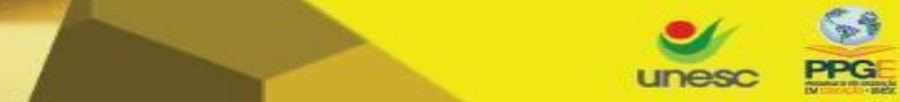

Criar Educação, Criciúma, v. 9, ํo 3, ago/dez. 2020 - PPGE - UNESC - ISSN 2317-2452

metodologia com definição da abordagem, tipo de pesquisa, procedimentos e instrumentos para coleta de dados, autores e resultados, buscando dessa forma, tornar mais eficiente os resumos de futuras pesquisas. Outro destaque que se faz necessário, diz respeito a dificuldade em encontrar as obras completas para leitura, pois nem na biblioteca depositária as mesmas estavam disponíveis para consulta.

Por fim, esse estudo é destinado aos professores do Ensino Fundamental Maior e Ensino Médio como instrumento de reflexão e apoio para elaboração e aplicação de práticas assertivas em sala de aula, onde os alunos desenvolvam uma postura indagativa em relação ao ato de conhecer, construindo de forma crítica e autônoma conhecimentos históricos significativos.

\section{Referências}

BASCHEIRA, Deise Angelica Pascali. Ensino de História e projeto integrado: possibilidades para a geração de aprendizagens significativas no ensino médio. Dissertação (Mestrado Profissional em História) - Pós-Graduação em História, Universidade De Caxias Do Sul. p. 133. 2015. Disponível em:

<https://bit.ly/2zLwNID>. Acesso em: 18 set. 2018.

BITTENCOURT, Circe Maria Fernandes. Ensino de história: fundamentos e métodos. 4. ed. São Paulo: Cortez 2011. (Coleção Docência em Formação. Série Ensino Fundamental).

BOGDAN, R. C.; BIKLEN, S. K. Investigação qualitativa em educação. Porto: Porto Editora, 1994.

BUCK-MORSS, Susan. Dialética do olhar: Walter Benjamin e o projeto das passagens. Belo Horizonte: Ed. UFMG; Chapecó: Ed. Universitária Argos, 2002.

DREHMER, Regina das Graças Figueredo Godinho. O Ensino de História na Educação Básica: reflexões sobre conceitos e metodologia. Dissertação (Mestrado em Educação) - Pós-Graduação em Educação, Universidade do Vale Do Itajaí. p. 108. 2008. Disponível em: < https://bit.ly/2NX8Z71 >. Acesso em: 18 set. 2018.

FAZENDA, Ivani C. A. Interdisciplinaridade: história, teoria e pesquisa. 11. ed. Campinas: Papirus, 1994.

Práticas interdisciplinares na escola. 2. Ed. São Paulo: Cortez,1993. 


\section{CRIAR EDUCAÇÃO}

Revista do Programa de Pós-Graduação em Educação - UNESC

(
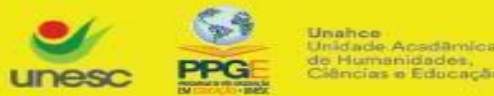

Criar Educação, Criciúma, v. 9, ํㅡㄴ, ago/dez. 2020 - PPGE - UNESC - ISSN 2317-2452

FIALHO, Lia M. F.; MACHADO, Charliton. J. dos S.; SALES, José A. M. de. As teorias da História e a História ensinada no ensino fundamental. Educativa, Goiânia, v. 19, n.1, p. 1043-1065, set./dez. 2016. Disponível em

<https://bit.ly/2BojqaL>Acesso em: 15 set. 2018.

KARNAL, Leandro. História na sala de aula: conceitos, práticas e propostas. São Paulo: Contexto, 2008.

HABERMAS, Jürgen. "A consciência de tempo da modernidade e sua necessidade de autocertificação". In: HABERMAS, Jürgen. $\mathbf{O}$ discurso filosófico da modernidade. São Paulo, Martins Fontes, 2000.

MARCONI, M. A.; LAKATOS, E. M. Metodologia Científica. 4. ed. São Paulo: Atlas, 2004

PINSKI, J.: PINSKI, C. B. Por uma história prazerosa e consequente. In: KARNAL, L. (Org.). História na sala de aula: conceitos, práticas e propostas. p. 17-36, 2008.

ROMANOWSKI, Joana P.; ENS, Romilda T. As pesquisas denominadas "estado da "arte em educação. Diálogo Educacional, Curitiba, v. 6, n. 19, p. 37-50, set./dez. 2006. Disponível em:

$<$ http://www2.pucpr.br/reol/pb/index.php/dialogo?dd1=237\&dd99=view $>$. Acesso em: 15 set. 2018.

SCHMIDT, M. A.; CAINELLI, M. Ensinar História. São Paulo: Scipione, 2004.

SILVA, Marco. Sala de aula interativa. 2. ed. Rio de Janeiro: Quartet, 2001.

SILVA, Raquel Brayner da. O Ensino de História os Anos Iniciais o Ensino

Fundamental: as políticas da Secretaria Municipal de Educação do Rio de Janeiro e a perspectiva do multiculturalismo. Dissertação (Mestrado Profissional em Ensino de História) - Pós-Graduação em Ensino de História, Universidade Federal do Rio de Janeiro. p. 93. 2016. Disponível em: < https://bit.ly/2Ng48J0 >. Acesso em: 18 set. 2018.

Recebido em agosto de 2020

Aceito em setembro de 2020 